\title{
Therapeutic hypothermia after nonshockable cardiac arrest: the HYPERION multicenter, randomized, controlled, assessor-blinded, superiority trial
}

Jean Baptiste Lascarrou ${ }^{1 *}$, Ferhat Meziani ${ }^{2}$, Amélie Le Gouge ${ }^{3,4}$, Thierry Boulain ${ }^{5}$, Jérôme Bousser ${ }^{6}$, Guillaume Belliard ${ }^{7}$, Pierre Asfar ${ }^{8}$, Jean Pierre Frat ${ }^{9}$, Pierre François Dequin ${ }^{10}$, Jean Paul Gouello ${ }^{11}$, Arnaud Delahaye ${ }^{12}$, Ali Ait Hssain ${ }^{13}$, Jean Charles Chakariann ${ }^{14}$, Nicolas Pichon ${ }^{15}$, Arnaud Desachy ${ }^{16}$, Fréderic Bellec ${ }^{17}$, Didier Thevenin ${ }^{18}$, Jean Pierre Quenot ${ }^{19}$, Michel Sirodot ${ }^{20}$, François Labadie ${ }^{21}$, Gaétan Plantefeve ${ }^{22}$, Dominique Vivier ${ }^{23}$, Patrick Girardie ${ }^{24}$, Bruno Giraudeau ${ }^{3,4}$, Jean Reignier ${ }^{1}$ and for the Clinical Research in Intensive Care and Sepsis (CRICS) Group and the HYPERION Study Group

\begin{abstract}
Background: Meta-analyses of nonrandomized studies have provided conflicting data on therapeutic hypothermia, or targeted temperature management (TTM), at $33^{\circ} \mathrm{C}$ in patients successfully resuscitated after nonshockable cardiac arrest. Nevertheless, the latest recommendations issued by the International Liaison Committee on Resuscitation and by the European Resuscitation Council recommend therapeutic hypothermia. New data are available on the adverse effects of therapeutic hypothermia, notably infectious complications. The risk/benefit ratio of therapeutic hypothermia after nonshockable cardiac arrest is unclear.
\end{abstract}

Methods: HYPERION is a multicenter (22 French ICUs) trial with blinded outcome assessment in which 584 patients with successfully resuscitated nonshockable cardiac arrest are allocated at random to either TTM between 32.5 and $33.5^{\circ} \mathrm{C}$ (therapeutic hypothermia) or TTM between 36.5 and $37.5^{\circ} \mathrm{C}$ (therapeutic normothermia) for 24 hours. Both groups are managed with therapeutic normothermia for the next 24 hours. TTM is achieved using locally available equipment. The primary outcome is day-90 neurological status assessed by the Cerebral Performance Categories (CPC) Scale with dichotomization of the results $(1+2$ versus $3+4+5)$. The primary outcome is assessed by a blinded psychologist during a semi-structured telephone interview of the patient or next of kin. Secondary outcomes are day-90 mortality, hospital mortality, severe adverse events, infections, and neurocognitive performance. The planned sample size of 584 patients will enable us to detect a 9\% absolute difference in day-90 neurological status with $80 \%$ power, assuming a 14\% event rate in the control group and a two-sided Type 1 error rate of 4.9\%. Two interim analyses will be performed, after inclusion of 200 and 400 patients, respectively.

Discussion: The HYPERION trial is a multicenter, randomized, controlled, assessor-blinded, superiority trial that may provide an answer to an issue of everyday relevance, namely, whether TTM is beneficial in comatose patients resuscitated after nonshockable cardiac arrest. Furthermore, it will provide new data on the tolerance and adverse events (especially infectious complications) of $T \mathrm{TM}$ at $32.5-33.5^{\circ} \mathrm{C}$.

Trial registration: ClinicalTrials.gov: NCT01994772.

Keywords: Cardiac arrest, Therapeutic hypothermia, Nonshockable rhythm

\footnotetext{
* Correspondence: jean-baptiste.lascarrou@chd-vendee.fr

${ }^{1}$ Medical-Surgical Intensive Care Unit, District Hospital Center, La Roche-sur-Yon, France

Full list of author information is available at the end of the article
} 
This manuscript was written in accordance with SPIRIT guidelines [1].

\section{Introduction}

\section{Background and rationale}

Cardiac arrest remains a major cause of mortality, as well as a cause of disability in survivors [2]. In Europe, 300000 cardiac arrests occur annually, of which 250000 are fatal. Even among patients with good prognostic factors, less than $50 \%$ are discharged from the hospital without severe neurological impairments $[3,4]$.

After early work suggesting a neuroprotective effect of hypothermia [5], animal studies provided evidence of neurological recovery after a period of controlled hypothermia [6]. These findings were confirmed by two randomized trials performed 10 years ago and published in the same issue of the New England Journal of Medicine. In both trials, therapeutic hypothermia significantly improved the neurological outcomes of patients with cardiac arrest in shockable rhythms (ventricular fibrillation or pulseless ventricular tachycardia). The first randomized trial was a European multicenter study in 275 patients managed with normothermia or hypothermia [7]. After 6 months, the proportion of patients with good neurological outcomes was $55 \%$ with hypothermia compared to only $39 \%$ with normothermia (odds ratio [OR], 1.4; $P=$ 0.009). In addition, mortality was significantly lower in the hypothermia group (OR, 0.74; $P=0.02)$. The second randomized trial was an Australian multicenter study in 77 patients managed with normothermia or hypothermia [8]. Again, good neurological outcomes were more common in the hypothermia group (OR, 1.88; $P=0.046)$, and this difference persisted in the multivariate analysis (OR, 5.25; $P=$ 0.011). However, hypothermia was not associated with a significant decrease in mortality (OR, 1.75; $P=0.145)$. A 2012 Cochrane review and metaanalysis confirmed the neuroprotective effect of hypothermia (relative risk [RR] of achieving a good neurological outcome, 1.55; 95\% confidence interval [95\% CI], 1.22-1.96) [9].

These data firmly establish the efficacy of TTM between $32^{\circ} \mathrm{C}$ and $34^{\circ} \mathrm{C}$ in improving the neurological outcomes of patients with shockable cardiac arrest. Guidelines issued in 2010 by the European Resuscitation Council (ERC) [10] and International Liaison Committee on Resuscitation (ILCOR) [11] recommend the routine use of TTM between $32^{\circ} \mathrm{C}$ and $34^{\circ} \mathrm{C}$ in comatose survivors of cardiac arrest with a nonshockable rhythm at arrival of emergency-care providers. These recommendations are based on a low level of evidence (Class IIb, LOE B). No randomized trials have assessed therapeutic hypothermia in survivors of nonshockable cardiac arrest. The recommendations are based on retrospective cohort studies and on prospective studies evaluating the feasibility of achieving a period of $32^{\circ}$ - $34^{\circ}$ TTM using invasive [12] or semi-invasive [13] devices. Nevertheless, the results of these studies are conflicting.

- A metaanalysis [14] showed no significant improvement in the 6-month neurological outcomes of 897 patients included in retrospective cohorts (OR, 0.93; 95\% CI, 0.88-1). In addition, two recent prospective cohort studies not included in the meta-analysis - one from France published in Circulation [15] and the other from Finland published in Intensive Care Medicine [16] - failed to demonstrate benefits from $32^{\circ}-34^{\circ}$ TTM in survivors of nonshockable cardiac arrest. Two German studies [17,18], one retrospective and the other prospective, showed no decrease in mortality when $32^{\circ}-34^{\circ}$ TTM was combined with optimal post-cardiac arrest care (including prompt coronary angiography if appropriate and hemodynamic parameter optimization). A very recent post-hoc analysis of the randomized TTM Study [19] showed no difference in neurological outcomes in the 178 patients with nonshockable rhythms [20].

- Other studies exhibiting similar methodological weaknesses (retrospective or prospective nonrandomized design without blinded assessment), in contrast, suggest a beneficial effect of hypothermia. Two retrospective Austrian studies showed better neurological outcomes with $32^{\circ}-34^{\circ}$ TTM in 374 patients [21] and 828 patients [22], respectively, with shockable or nonshockable cardiac arrest. Finally, a case-control study of 100 patients with nonshockable cardiac arrest reported by an American group showed better neurological outcomes with $32^{\circ}-34^{\circ}$ TTM [23].

Three factors probably explain most of the difference in $32^{\circ}-34^{\circ}$ TTM effects between patients with shockable versus nonshockable cardiac arrest. First, patients with shockable cardiac arrest constitute a fairly uniform population of predominantly male individuals with a cardiac cause (ST-segment-elevation myocardial infarction) potentially treatable by coronary angiography and appropriate percutaneous coronary intervention [24]. In contrast, nonshockable cardiac arrest can occur in a wide variety of settings, for instance as a complication of a primary shockable rhythm or during asphyxia due to hanging, drowning, or gastric-content aspiration. Second, nonshockable cardiac arrest carries a poorer prognosis than does shockable cardiac arrest: survival with good neurological function (CPC 1 or 2) is nearly $40 \%$ after shockable cardiac arrest compared to less than $20 \%$ after nonshockable cardiac arrest $[25,26]$. Two factors associated with a better prognosis of cardiac arrest are less common in nonshockable than shockable rhythms, namely, presence of a witness [27] and cardiac origin of 
the arrest [28]. Consequently, demonstrating a beneficial effect of a therapeutic intervention requires a larger sample size in studies of nonshockable compared to shockable cardiac arrest. Third, a corollary to the first and second factors is that the effects of interventions for cardiac arrest may differ markedly between patients with nonshockable and shockable cardiac arrest. For example, although recent data argue against epinephrine treatment during shockable cardiac arrest [29,30], other studies strongly support the earliest possible administration of epinephrine during nonshockable cardiac arrest [31].

Studies of neonatal hypoxia have produced convincing evidence that $32^{\circ}-34^{\circ}$ TTM diminishes mortality and improves neurological outcomes $[32,33]$. Although brain plasticity differs between neonates and adults, this evidence strongly supports a beneficial effect of $32^{\circ}-34^{\circ}$ TTM in patients with cardiac arrest due only to anoxia. A retrospective study showed that the mortality rate after attempted suicide by hanging with cardiac arrest was as high as $90 \%$ [34]. In contrast, in two studies of $32^{\circ}$ $34^{\circ}$ TTM used to treat patients with severe asphyxia, mortality was less than 67\% [35] and 45\% [36], respectively. These findings support evaluation of $32^{\circ}$ $34^{\circ}$ TTM in patients with nonshockable cardiac arrest due to noncardiac causes [37].

The safety profile of $32^{\circ}-34^{\circ}$ TTM was good in two early studies $[7,8]$. More recently, however, an increased risk of infection [38], including pneumonia [39] was reported. In addition, $32^{\circ}-34^{\circ}$ TTM usually requires neuromuscular blockade, which interferes with the neurological assessments, thereby extending ICU stay length and diminishing the ability to identify seizures and to provide optimal seizure prevention [40]. Activation of the inflammatory cascade may occur during $32^{\circ}-34^{\circ}$ TTM [41], leading to a risk of rebound hyperthermia, which may adversely affect patient outcomes $[42,43]$. Similarly, $32^{\circ}-34^{\circ}$ TTM may exert negative hemodynamic effects, increasing vasoactive drug requirements [44], a point of particular concern given the poor prognosis of post-resuscitation shock [16].

In sum, the risk/benefit ratio of $32^{\circ}-34^{\circ}$ TTM in patients with nonshockable cardiac arrest remains unclear. This uncertainty has led to a call for randomized controlled trials [45].

\section{Objectives}

\section{Primary objective}

To determine whether TTM between $32.5^{\circ} \mathrm{C}$ and $33.5^{\circ} \mathrm{C}$ (32.5 $\left.-33.5^{\circ} \mathrm{TTM}\right)$ for $24 \mathrm{~h}$ improves day-90 neurological outcomes compared to TTM between $36.5^{\circ} \mathrm{C}$ and $37.5^{\circ} \mathrm{C}$ in survivors of nonshockable cardiac arrest.

\section{Secondary objectives}

To determine whether $32.5^{\circ}-33.5^{\circ}$ TTM for $24 \mathrm{~h}$ decreases mortality and morbidity (ICU and hospital stay lengths) and to assess the safety of $32.5^{\circ}-33.5^{\circ}$ TTM.

\section{Trial design}

HYPERION is a multicenter, randomized, controlled, assessor-blinded, superiority trial with two parallel groups and a primary endpoint of day-90 neurological outcome.

\section{Methods: participants, interventions, and outcomes \\ Study setting}

The HYPERION trial is taking place in 22 ICUs in 22 hospitals (8 university and 14 general hospitals) in France.

\section{Eligibility criteria}

Figure 1 shows the patient eligibility criteria and study protocol.

\section{Inclusion criteria}

Patients must meet both of the following criteria:

- Cardiac arrest in nonshockable rhythm and

- Glasgow Coma Scale score $\leq 8$. In patients receiving sedative therapy at ICU admission, the Glasgow Coma Scale score assessed by the emergency physician just before sedative therapy initiation is used.

\section{Exclusion criteria}

Patients fulfilling one or more of the following criteria are not included:

- No-flow time $>10$ min (time from collapse to initiation of external cardiac massage);

- Low-flow time $>60$ min (time from initiation of external cardiac massage to return of spontaneous circulation).

- Major hemodynamic instability (defined as a continuous epinephrine or norepinephrine infusion at a flow rate $>1 \mu \mathrm{g} / \mathrm{Kg} / \mathrm{min}$ )

- Time from cardiac arrest to study inclusion $>300 \mathrm{~min}$

- Moribund patient

- Child C cirrhosis of the liver

- Age $<18$ years

- Pregnant or breastfeeding woman

- Correctional facility inmate

- Previous inclusion in another randomized clinical trial on cardiac arrest with day-90 neurological outcome as the primary endpoint

- Patient without health insurance

- Decision by the patient or next of kin to refuse the study. 


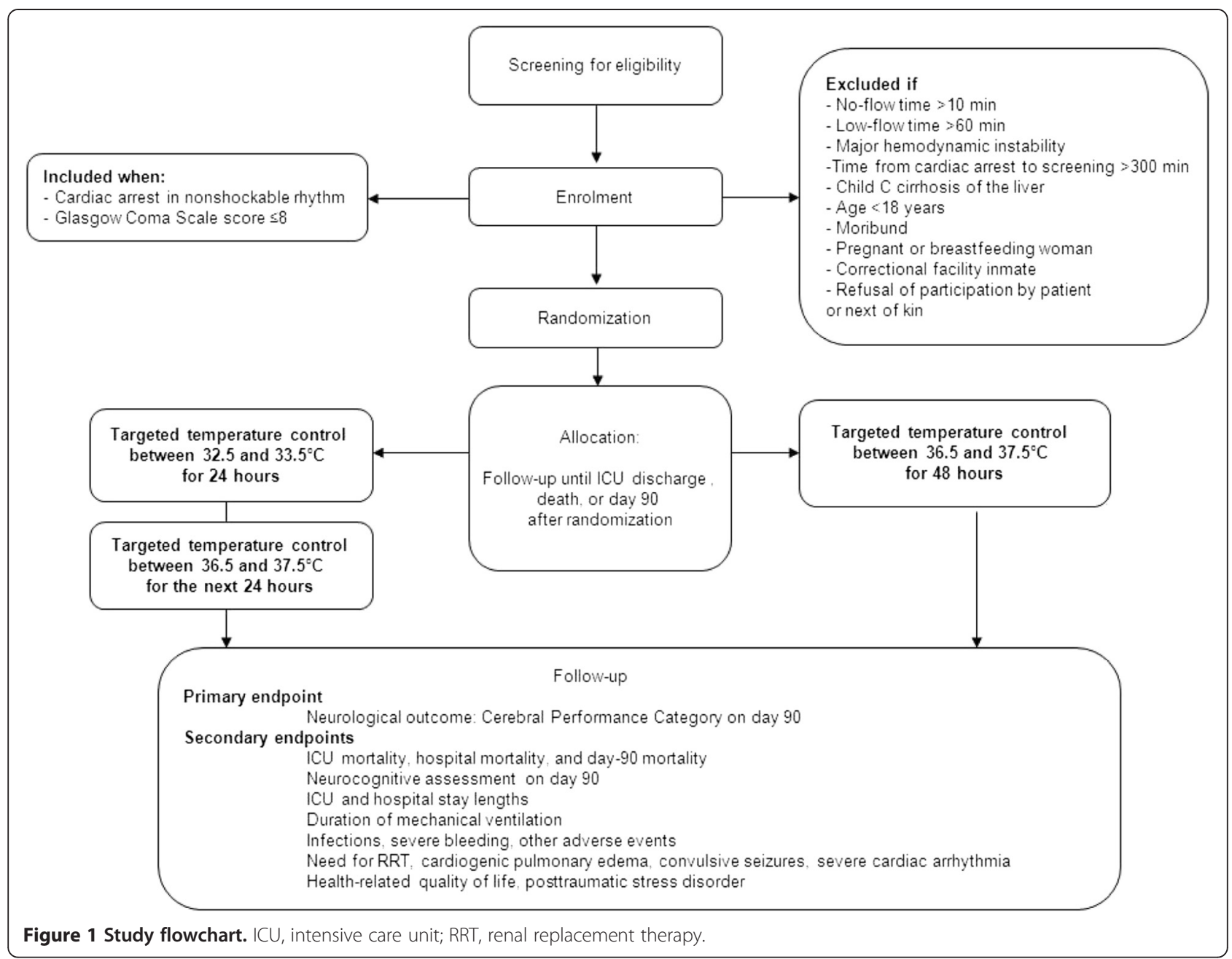

\section{Interventions}

Patients allocated at random to $32.5^{\circ}-33.5^{\circ}$ TTM have hypothermia induced then maintained for $24 \mathrm{~h}$. Slow rewarming to $36.5^{\circ}-37.5^{\circ}$ is then achieved and maintained for $24 \mathrm{~h}$. Patients in the control group have their body temperature maintained at $36.5^{\circ}-37.5^{\circ} \mathrm{C}$ for $48 \mathrm{~h}$. Figure 2 provides details on the study protocol and randomization arms.

To induce and maintain $32.5^{\circ}-33.5^{\circ}$ TTM, each center follows its standard protocol. Thus, the method may involve active internal cooling using a specific device, active external cooling using a specific device, or active external cooling without a specific device. No trial using mortality or neurological outcome as the endpoint has demonstrated that one method is better than the others $[46,47]$. Infusion of cold fluid $\left(4^{\circ} \mathrm{C}\right)$ is recommended to expedite achievement of the target temperature [48-50]. The same methods are used to manage hyperthermia (above $37.5^{\circ} \mathrm{C}$ ) in both groups. The study protocol involves standardization of several parameters including sedation, neuromuscular blockade, and management of expected adverse events. The use of medications (e.g., acetaminophen or aspirin) to maintain normothermia is discouraged in both groups [51]. Figure 2 recapitulates the therapeutic interventions.

\section{Concomitant medications/treatments in both groups}

Sedation In the $32.5^{\circ}-33.5^{\circ}$ TTM group, all patients receive sedation with midazolam or propofol combined with fentanyl or sufentanil according to the standard sedation protocol in each participating ICU. Doses are adjusted to obtain a Richmond Agitation Sedation Scale score of -5 [52] and are tapered when body temperature is above $36^{\circ} \mathrm{C}$ during the rewarming phase.

In the $36.5^{\circ}-37.5^{\circ} \mathrm{TTM}$ group, all patients receive sedation with midazolam or propofol combined with fentanyl or sufentanil for the first $12 \mathrm{~h}$ after randomization. Doses are adjusted to obtain a Richmond Agitation Sedation Scale score of 0. As indicated in the 2010 ILCOR guidelines [10], no data exist to support the use of sedative agents during $\mathrm{TTM}$ at $37^{\circ} \mathrm{C}$. The use of sedative 


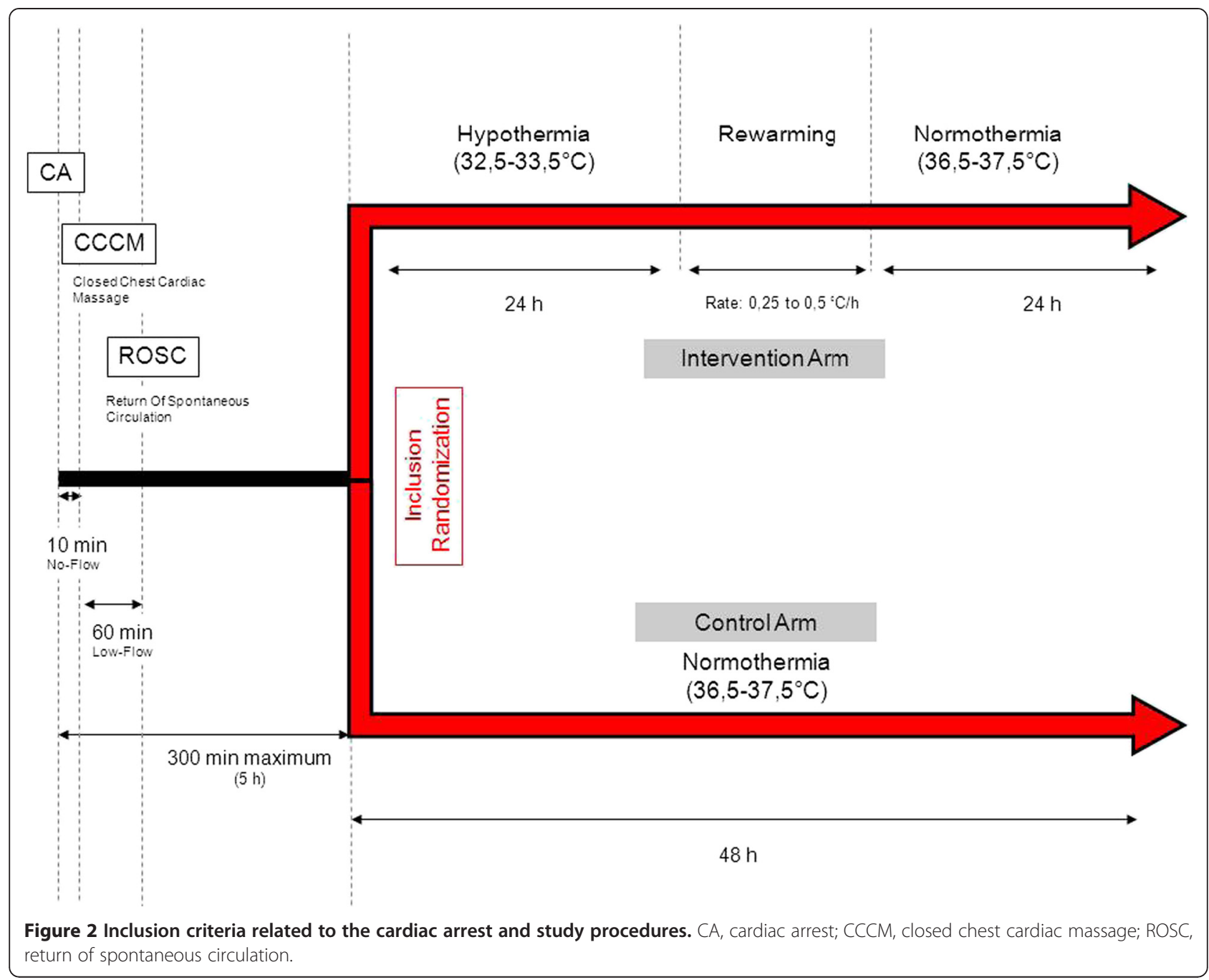

agents during $\mathrm{TTM}$ at $37^{\circ} \mathrm{C}$ is therefore restricted, to shorten the time to awakening.

Shivering and neuromuscular blockade Persistent shivering is treated according to a previously published three-step protocol [53] that has been adapted since the publication of the Bedside Shivering Assessment Score (BSAS) $[54,55]$. The goal is to obtain a BSAS $\leq 1$.

- Step 1, single intravenous bolus of a hypnotic agent and an opioid, in doses equal to the hourly infusion rates of hypnotic and opioid drugs (i.e., 5-mg intravenous midazolam bolus if the continuous midazolam infusion rate was $5 \mathrm{mg} / \mathrm{h}$ );

- Step 2, intravenous bolus of a nondepolarizing neuromuscular blocker (i.e., $10 \mathrm{mg}$ of cisatracurium);

- and Step 3, continuous infusion of a nondepolarizing neuromuscular blocker (i.e., cisatracurium in an initial dose of $10 \mathrm{mg} / \mathrm{h}$ ), with a BSAS target of $\leq 1$; during rewarming, the infusion may be stopped when the core body temperature increases above $35^{\circ} \mathrm{C}$.

\section{Concomitant prevention of systemic secondary brain injury} in both groups

Arterial hypotension Hemodynamic evaluations are conducted to allow blood volume optimization. Hypovolemia is managed with crystalloid or colloid infusion, according to standard practice in the participating ICU. Subsequent evaluations are performed as dictated by the course of the hemodynamic parameters. In accordance with guidelines [10], and in the absence of specific randomized studies, a mean arterial pressure of $65 \mathrm{mmHg}$ and, if measured, central venous oxygen saturation $\left(\mathrm{ScvO}_{2}\right) \geq 70 \%$ are considered reasonable targets [11]. The introduction of vasoactive drug treatment is at the discretion of the physicians, who follow international guidelines [10] and local protocols. 
Hypoxemia $\mathrm{PaO}_{2}$ and pulse oximetry $\left(\mathrm{SpO}_{2}\right)$ are monitored with the goal of maintaining $\mathrm{SpO}_{2} \geq 92 \%$, as recommended [10].

Hypercapnia and hypocapnia $\mathrm{PaCO}_{2}$ and end-tidal partial $\mathrm{CO}_{2}$ pressure are monitored with the goal of maintaining $\mathrm{PaCO}_{2}$ between 35 and $40 \mathrm{mmHg}$ after correcting for body temperature [56].

Anemia The goal is to maintain hemoglobin $\geq 7 \mathrm{~g} / \mathrm{dL}$ in patients without ischemic heart disease and $\geq 10 \mathrm{~g} / \mathrm{dL}$ in those with ischemic heart disease, as recommended [10].

Blood sugar control A protocol for monitoring blood glucose (or capillary blood glucose) is available to the physician in charge of the patient. In accordance with guidelines [10], specific treatment is recommended in patients with blood glucose values outside the 3.33-10 $\mathrm{mmoL} / \mathrm{L}(60-180 \mathrm{mg} / \mathrm{dL})$ range.

\section{Withdrawal of life-sustaining treatments in both groups}

Each participating ICU uses its own specific protocol to make decisions about withdrawing life-sustaining treatments. Routine evaluation of the neurological prognosis by an out-of-house consultant is not performed. Nevertheless, to ensure that neurological outcome prediction is performed according to the most recent evidence, our protocol includes the following three measures [57].

1. During the trial preparation phase, all investigators received specific instructions that decisions to withdraw life-sustaining treatments must comply with guidelines issued in 2012 by the ethics committee of the French Intensive Care Society (SLRF) [58]. According to these guidelines, multiple criteria should be used to predict the neurological outcome. Taken individually, the following criteria predict an unfavorable outcome of postanoxic coma after cardiac arrest: bilateral absence of the pupillary response to light or corneal reflex on the third day; bilateral absence of a motor response to pain on the third day; persistent generalized myoclonus during the first 24 hours; an EEG showing an isoelectric line or burst-suppression or anoxic status epilepticus during the first week; and bilateral absence of early cortical activity (N20) detected by somatosensory evoked potentials after the third day and after the end of hypothermia. Although wrongly predicting an unfavorable outcome cannot be entirely avoided, the risk of this occurring can be decreased by relying on more than one criterion. Another important point when seeking to improve prediction accuracy is careful and exhaustive collection of the most severe results from evaluations of each criterion [58].
2. During the trial, the investigators receive newsletters that detail any new information on predicting neurological outcomes after cardiac arrest and any new French or international guidelines about patients with coma after cardiac arrest.

3. The eCRF includes a specific section for collecting the following data in patients with a decision to withdraw life-sustaining treatments: clinical, laboratory, and imaging-study findings on the day the decision was taken; details on the decision-making process; and details on implementation of the decision.

\section{Outcomes}

\section{Primary outcome measure}

- Neurological status 90 days after randomization according to the CPC Scale [59-61]. The CPC is assessed during a semi-structured telephone interview [62]. All interviews of study patients are performed by a single psychologist specifically trained for the study and blinded to the treatment group.

\section{Secondary outcome measures}

- ICU mortality

- Hospital mortality

- Day-90 mortality

- Day-90 quality of life evaluated using the 36-item Short Form for Health Survey $[63,64]$

- Day-90 patient self-sufficiency evaluated using the Activities of Daily Living (ADL) Index [65,66], modified Barthel's ADL index [67], and two simple standardized questions [68]

- Day-90 neurocognitive status evaluated using the telephone version of the Mini-Mental State Examination [69]

- Estimated number of patients with symptoms of posttraumatic stress on day 90 as assessed using the revised Impact of Events Scale (IES) [70].

- ICU stay length

- Duration of mechanical ventilation, defined as the time from randomization to final successful extubation. Extubation followed by breathing without invasive ventilatory assistance (not including noninvasive ventilation) for $48 \mathrm{~h}$ is classified as successful [71].

- Incidence of severe bleeding defined as red-bloodcell transfusion or surgery for intracranial hemorrhage

- Incidence of nosocomial infections in the ICU

- Incidence of aspiration pneumonia in the ICU, with aspiration pneumonia defined as pneumonia diagnosed within $48 \mathrm{~h}$ of mechanical ventilation initiation 
- Incidence of ventilator-acquired pneumonia in the ICU

- Incidence of nosocomial urinary tract infections in the ICU

- Incidence of intravascular catheter infections in the ICU

- Need for vasoactive drug therapy within the first $48 \mathrm{~h}$

- Need for renal replacement therapy

- Number of episodes of cardiogenic pulmonary edema

- Number of episodes of seizures

- Number of episodes of severe cardiac arrhythmia.

\section{Participant timeline}

Participant timeline is figured on Table 1.

\section{Sample size}

We expect that $14 \%$ of patients in the $36.5^{\circ}-37.5^{\circ}$ TTM group will be CPC 1 or 2 on day 90 and that this proportion will increase by $9 \%$ with $32.5^{\circ}-33.5^{\circ}$ TTM. With a twosided Type I error of 5\% and $80 \%$ power, and given that two interim analyses will be performed, the required number of patients is 292 per group, i.e., 584 patients in all.

\section{Recruitment}

Patient inclusion started in January 2014 in 22 French ICUs. Enrolment is ongoing. As of February 2, 2015, 161 patients had been included.

\section{Methods: assignment of interventions Allocation}

Randomization is centralized, web-based, and accessible 24 hours a day. Randomization is balanced (1:1) and stratified by center and cause of cardiac arrest (probable cardiac cause such as cardiac ischemia or probable noncardiac cause).

\section{Sequence generation}

The randomization sequence was generated by a statistician from the INSERM CIC 1415 not involved in patient recruitment. The sequences are implemented in the software used to collect the data (eCRF).

\section{Blinding}

Blinding of healthcare workers, patients (despite the sedation), and families to the type of temperature management is not feasible. However, the primary outcome is assessed by a psychologist blinded to the treatment arm, during a semi-structured telephone interview [62].

\section{Methods: data collection, management, and analysis}

Data collection and management

The study data are recorded in an electronic web-based case-report form (eCRF) from the medical records of each patient (source data), by trial-site personnel. The data manager, in cooperation with the coordinating investigator, establishes the trial database by exporting data from the eCRF. Any protocol deviations are recorded in either the eCRF or the medical records.

\section{Statistical methods Statistical analysis}

A predefined statistical analysis plan will be followed. The intention-to-treat principle will be applied. The statistical report will incorporate the data recommended by the CONSORT Statement extension for nonpharmacologic treatment interventions [72].

Table 1 Participant timeline

\begin{tabular}{|c|c|c|c|c|c|c|c|c|}
\hline & Inclusion & Do & D1 & D2 & D3 & D4 & Dn & D90 \\
\hline Eligibility: check inclusion and exclusion criteria & $x$ & & & & & & & \\
\hline Informed consent & $x$ & & & & & & & \\
\hline Demographic data & $x$ & & & & & & & \\
\hline Randomization & $x$ & & & & & & & \\
\hline Patient characteristics and Physical examination & $x$ & & & & & & & \\
\hline Vital signs & $x$ & & & & & & & \\
\hline Coronary angiography & $x$ & & & & & & $x$ & \\
\hline Mechanical ventilation & & $x$ & $x$ & $x$ & $x$ & $x$ & $x$ & \\
\hline Biology & & $x$ & $x$ & $x$ & $x$ & $x$ & $x$ & \\
\hline Electrocardiogram & $x$ & & $x$ & $x$ & $x$ & & & \\
\hline Physical examination & $x$ & & $x$ & $x$ & $x$ & $x$ & $x$ & \\
\hline Treatments & & $x$ & $x$ & $x$ & $x$ & $x$ & $x$ & \\
\hline Vital status & & $x$ & $x$ & $x$ & $x$ & $x$ & $x$ & $x$ \\
\hline Telephone interview by psychologist & & & & & & & & $x$ \\
\hline
\end{tabular}


Descriptive statistics will be used to compare the two randomization groups, without statistical testing. The chi-squared test will be performed to compare the primary endpoint in the two groups. Two interim analyses will be conducted, after the inclusion of 200 and 400 patients, respectively. The rule developed by Peto and Haybittle [73] will be applied, with the significance level set at 0.001 for both interim analyses and the significance level associated with the final analysis set at 0.049 to maintain an overall Type I error of $5 \%$.

Secondary endpoints evaluating binary variables (need for renal replacement therapy, acute cardiogenic pulmonary edema, and binary day-90 neurological outcome) will be compared using the chi-squared test. Secondary endpoints evaluating quantitative variables (biological tests, stay lengths, and mechanical ventilation duration) will be compared using the Student $t$ test or Mann-Whitney test.

\section{Subgroup analysis}

- Based on a previous trial showing that benefits from $33^{\circ} \mathrm{C}$ TTM in cardiac arrest were greatest in the subgroups of patients with long no-flow times and low-flow times (most notably longer than 15 minutes) [74-76], we plan to perform analyses in these two subgroups.

- We will also analyze other subgroups defined based on the following prognostic factors: presence of a witness (yes/no); in-hospital versus out-of-hospital cardiac arrest; and probable cardiac origin (yes/no), which was a stratification variable.

- Finally, to take the baseline cerebral performance category into account, we will compare subgroups with $C P C 1-2$ versus $C P C ~ 3-4$ before randomization.

\section{Methods: monitoring Data monitoring}

The results of the interim analysis will be provided to the Data and Safety Monitoring Board (DSMB), which will make recommendations about whether to continue or stop the trial. The DSMB is composed of 3 physicians not otherwise involved in the trial. For both interim analyses, the DSMB will have access to unblinded results on day- 90 CPC, day-90 mortality, and secondary safety outcomes (dialysis, infection, and seizure event). The results of the interim analysis will not be disclosed unless they lead the DSMB to request premature trial discontinuation. The DSMB members are Prof. Pierre Francois Laterre (Department of Critical Care Medicine, Cliniques Universitaires Saint Luc, Université Catholique de Louvain, Avenue Hippocrate, 10, 1200 Brussels, Belgium), Prof. Eric Maury (Medical ICU, Saint-Antoine Teaching Hospital, Assistance Publique-Hôpitaux de Paris, 184 rue du Faubourg Saint-
Antoine, Cedex 12, Paris 75571, France), and Prof. Bruno Megarbane (Medical ICU, Lariboisière Teaching Hospital, Paris-Diderot University, Paris, France).

\section{Harms}

The trial may be temporarily stopped for an individual patient, at the discretion of the attending physician, in case of major serious adverse events suspected to be associated with the type of temperature management. According to French law, as the strategies used in both study arms are classified as standard care, no specific reporting procedure for unexpected serious adverse events is planned. Follow-up data on expected serious adverse events are recorded in the eCRF; these events may include bleeding, cardiogenic pulmonary edema, renal replacement therapy, infection, and withholding or withdrawing of life-sustaining treatments.

\section{Ethics and dissemination}

\section{Research ethics approval}

The trial is conducted in compliance with the current version of the Helsinki Declaration and good clinical practice guidelines. The research project was approved by the ethics committee of the French Intensive Care Society (SRLF) on October 6, 2011, and by the appropriate Ethics Committee for the Protection of Patients (CPP Ouest 2) in Angers, France, on June 11, 2013.

\section{Consent or assent}

According to French law, because the strategies used in both study groups are considered components of standard care, there is no requirement for consent. Instead, information of the patients or next of kin is required. All patients assessed for enrolment in the trial are comatose and therefore unable to understand information. Their next of kin is informed about the trial and confirms in writing that he/she has received this information. If no next of kin can be contacted during screening for the study, trial inclusion is conducted as an emergency procedure by the ICU physician, in compliance with French law. Patients who regain consciousness are informed about the trial as soon as possible and asked for written confirmation that they received this information.

A patient may withdraw from the trial at any time if the person informed about the study (patient or next of kin) is unwilling to continue in the trial. The person requesting trial withdrawal is asked for permission to continue data recording and to perform the part of the day-90 telephone interview consisting in a semistructured CPC assessment; patients who accept this partial withdrawal modality have their data kept in the study analyses. Patients who request full withdrawal have all their data deleted. 


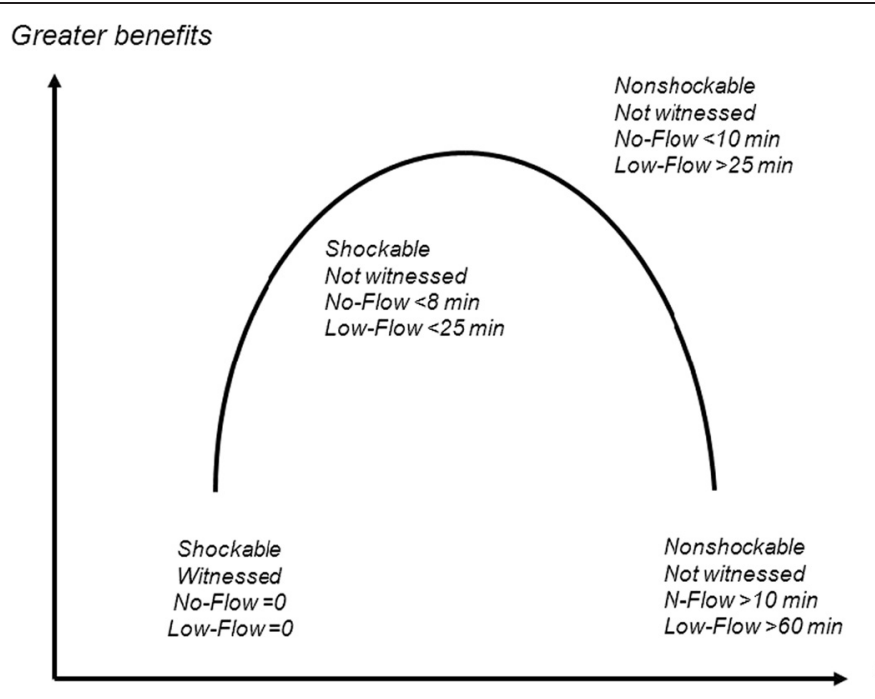

Poorer

prognosis

Figure 3 Benefits from targeted temperature management in relation to patient's prognosis.

Patients transferred to another ICU are withdrawn from the trial if the transfer occurs before the end of the TTM phase, unless the new ICU is participating in the trial, in which case the patient is kept in the same treatment group. All patients transferred to another ICU are followed for determination of the primary endpoint.

\section{Confidentiality}

The study data will be handled as requested by the French Data Protection Authority (Commission Nationale de l'Informatique et des Libertés). All original records will be kept on file at the trial sites or the coordinating data managing center for 15 years. The clean electronic trial database file will be anonymized and kept on file for 15 years.

\section{Discussion}

Few data are available to explain the discrepancies among the findings from trials of TTM, most notably in patients with nonshockable cardiac arrest. The beneficial effects of $32.5^{\circ}-33.5^{\circ}$ TTM probably vary with the degree of brain damage at treatment initiation. The ischemic penumbra concept developed for stroke is probably applicable to the brain damage seen after cardiac arrest. In a study of patients with nonshockable cardiac arrest, the benefits from $32.5^{\circ}-33.5^{\circ}$ TTM were greatest when the no-flow time was

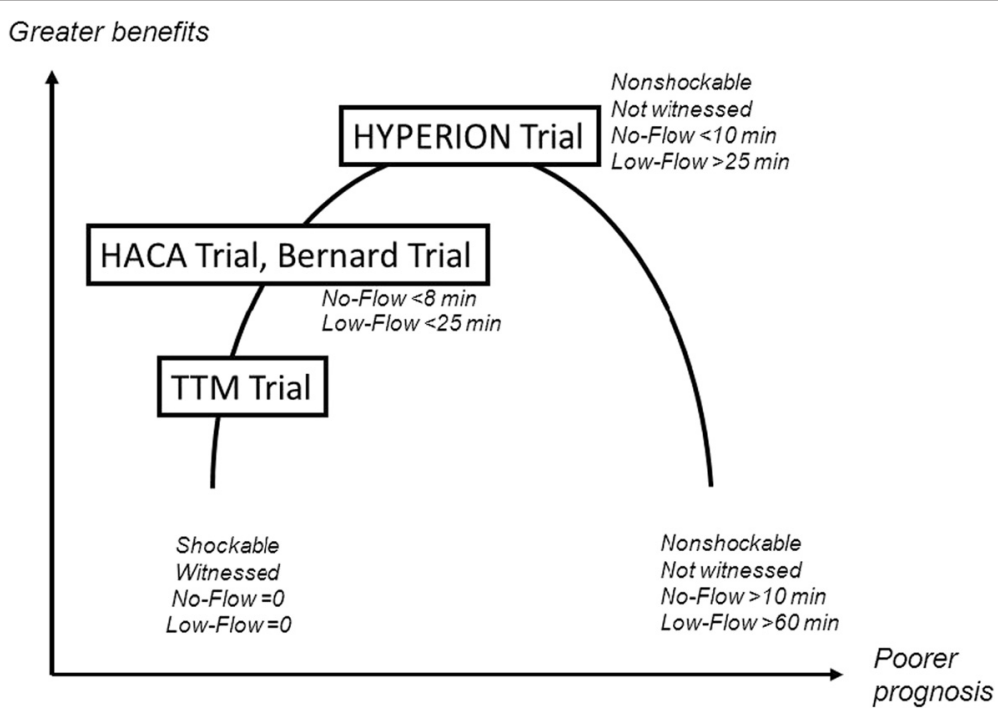

Figure 4 Benefits from targeted temperature management in relation to patient's prognosis documented in previous studies and expected in the HYPERION trial. 
longer than 8 minutes [76]. Similarly, in another study of patients with shockable or nonshockable cardiac arrest, $32.5^{\circ}-33.5^{\circ}$ TTM was most effective in the subgroup whose time from cardiac arrest to the return of spontaneous circulation (ROSC) was longer than 15 minutes [74]. In a previous pilot study, $32^{\circ}$ was better than $34^{\circ}$ as the target temperature [77]. The TTM Trial published in The New England Journal Medicine [19] showed that TTM at $36^{\circ} \mathrm{C}$ was similar to TTM at $33^{\circ} \mathrm{C}$ in patients with good prognostic factors including witnessed cardiac arrest in shockable rhythm with short no-flow and low-flow times compared to patients enrolled in earlier trials and having less favorable prognostic characteristics $[7,8]$. Figure 3 reports the estimated benefits of TTM and Figure 4 the effects documented in previous studies and the expected effects in the HYPERION trial.

Our decision to use a 24-h period of normothermia after $32.5^{\circ}-33.5^{\circ}$ TTM was based on reports that rebound hyperthermia adversely affected the outcomes of patients with cardiac arrest $[42,78]$. Whether rebound hyperthermia is a causal or an associated factor for mortality or neurological outcome after $32.5^{\circ}-33.5^{\circ}$ TTM is unclear. However, the TTM Trial [19] established the importance of preventing hyperthermia after cardiac arrest.

In conclusion, the HYPERION trial is the first registered randomized controlled trial evaluating the potential benefits of $32.5^{\circ}-33.5^{\circ}$ TTM on the neurological outcome of patients after nonshockable cardiac arrest.

\footnotetext{
Abbreviations

BSAS: Bedside shivering assessment scale; CPC: Cerebral performance category; eCRF: Electronic case-report form; ICU: Intensive care unit; ROSC: Return of spontaneous circulation; TTM: Targeted temperature management.
}

\section{Competing interests}

The authors declare that they have no competing interests.

\section{Authors' contributions}

$J B L$ prepared the first draft of the manuscript. JBL, BG, and JR wrote the manuscript. JBL, ALG, BG, and JR participated in designing the HYPERION study. ALG and BG wrote the statistical analysis plan and estimated the sample size. JBL obtained funding for the study. All authors contributed to acquire the study data. All authors revised the manuscript for important intellectual content and read and approved the final version of the manuscript.

\section{Acknowledgments}

We thank the clinical staff at the trial sites; A. Wolfe, MD, for assistance in preparing and reviewing the manuscript; G. Colin, MD, S. Martin PharmD, and E Greau, RN, for reviewing the manuscript; and G. Dolbeau for managing the database.

\section{Funding}

This study was supported by a grant from the French Ministry of Health, which is the only study funder (Programme Hospitalier de Recherche Clinique $\left.2013 n^{\circ} \mathrm{PHRCI} 1369057 \mathrm{~N}\right)$. The funder has no role in the design, management, analysis, or reporting of the trial.

\section{Roles and responsibilities-contributorship}

This study was sponsored by the District Hospital Centre in La Roche Sur Yon, France. The sponsor is responsible for promoting data quality and checking data accuracy and completeness.

Sponsor contact: Dr Jerome Dimet; +33251446161; jerome.dimet@chdvendee.fr.

\section{Author details}

${ }^{1}$ Medical-Surgical Intensive Care Unit, District Hospital Center, La Roche-sur-Yon, France. ${ }^{2}$ Medical Intensive Care Unit, University Hospital Center, University of Strasbourg, Strasbourg, France. ${ }^{3}$ INSERM CIC1415, CHRU de Tours, Tours, France. ${ }^{4}$ Université François-Rabelais de Tours, PRES Centre-Val de Loire Université, Tours, France. ${ }^{5}$ Medical Intensive Care Unit, Regional Hospital Center, Orleans, France. ${ }^{6}$ Medical-Surgical intensive Care Unit, General Hospital Center, Saint Brieuc, France. ${ }^{7}$ Medical Intensive Care Unit, South Brittany General Hospital Center, Lorient, France. ${ }^{8}$ Medical Intensive Care Unit, University Hospital Center, Angers, France. ${ }^{9}$ Medical Intensive Care Unit, University Hospital Center, Poitiers, France. ${ }^{10}$ Medical Intensive Care Unit, University Hospital Center, Tours, France.

${ }^{11}$ Medical-Surgical Intensive Care Unit, General Hospital Center, Saint Malo, France. ${ }^{12}$ Medical-Surgical Intensive Care Unit, General Hospital Center, Rodez, France. ${ }^{13}$ Medical Intensive Care Unit, University Hospital Center, Clermond-Ferrand, France. ${ }^{14}$ Medical-Surgical Intensive Care Unit, General Hospital Center, Roanne, France. ${ }^{15}$ Medical-Surgical Intensive Care Unit, University Hospital Center, Limoges, France. ${ }^{16}$ Medical-Surgical Intensive Care Unit, General Hospital Center, Angouleme, France. ${ }^{17}$ Medical-Surgical Intensive Care Unit, General Hospital Center, Montauban, France.

${ }^{18}$ Medical-Surgical Intensive Care Unit, General Hospital Center, Lens, France.

${ }^{19}$ Medical Intensive Care Unit, University Hospital Center, Dijon, France.

${ }^{20}$ Medical-Surgical Intensive Care Unit, General Hospital Center, Annecy,

France. ${ }^{21}$ Medical-Surgical Intensive Care Unit, General Hospital Center, Saint Nazaire, France. ${ }^{22}$ Medical-Surgical Intensive Care Unit, General Hospital Center, Argenteuil, France. ${ }^{23}$ Medical-Surgical Intensive Care Unit, General Hospital Center, Le Mans, France. ${ }^{24}$ Medical Intensive Care Unit, University Hospital Center, Lille, France.

Received: 6 November 2014 Accepted: 11 February 2015 Published online: 07 March 2015

\section{References}

1. Chan AW, Tetzlaff JM, Gotzsche PC, Altman DG, Mann H, Berlin JA, et al. SPIRIT 2013 explanation and elaboration: guidance for protocols of clinical trials. BMJ. 2013;346:e7586.

2. Handley AJ, Koster R, Monsieurs K, Perkins GD, Davies S, Bossaert L. European Resuscitation Council Guidelines for Resuscitation 2005: Section 2. Adult basic life support and use of automated external defibrillators. Resuscitation. 2005;67:S7-23.

3. Grubb NR, Fox KAA, Elton RA. In-hospital mortality after out-of-hospital cardiac arrest. Lancet. 1995;346:417-21.

4. Lindner TW, Langorgen J, Sunde K, Larsen Al, Kvaloy JT, Heltne JK, et al. Factors predicting the use of therapeutic hypothermia and survival in unconscious out-of-hospital cardiac arrest patients admitted to the ICU. Crit Care. 2013;17:R147

5. Rosomoff HL, Holaday DA. Cerebral Blood Flow and Cerebral Oxygen Consumption During Hypothermia. Am J Physiol. 1954;179:85-8.

6. Safar P, Xiao F, Radovsky A, Tanigawa K, Ebmeyer U, Bircher N, et al. Improved cerebral resuscitation from cardiac arrest in dogs with mild hypothermia plus blood flow promotion. Stroke. 1996;27:105-13.

7. The Hypothermia after Cardiac Arrest Study Group. Mild therapeutic hypothermia to improve the neurologic outcome after cardiac arrest. N Engl J Med. 2002;346:549-56.

8. Bernard SA, Gray TW, Buist MD, Jones BM, Silvester W, Gutteridge G, et al. Treatment of comatose survivors of out-of-hospital cardiac arrest with induced hypothermia. New Engl J Med. 2002;346:557-63.

9. Arrich J, Holzer M, Havel C, Mullner M, Herkner H. Hypothermia for neuroprotection in adults after cardiopulmonary resuscitation. Cochrane Database Syst Rev. 2012;9:,CD004128.

10. Peberdy M, Callaway C, Neumar R, Geocadin R, Zimmerman J, Donnino M, et al. Part 9: post-cardiac arrest care. American Heart Association Guidelines for Cardiopulmonary Resuscitation and Emergency Cardiovascular Care. Circulation. 2010;2010:S768-86. 
11. Nolan JP, Soar J, Zideman DA, Biarent D, Bossaert LL, Deakin C, et al. European Resuscitation Council Guidelines for Resuscitation 2010 Section 1. Executive summary. Resuscitation. 2010;81:1219-76

12. Laurent I, Adrie C, Vinsonneau C, Cariou A, Chiche J-D, Ohanessian A, et al. High-Volume Hemofiltration After Out-of-Hospital Cardiac Arrest: A Randomized Study. J Am Coll Cardiol. 2005:46:432-7.

13. Hachimi-Idrissi S, Corne L, Ebinger G, Michotte Y, Huyghens L. Mild hypothermia induced by a helmet device: a clinical feasibility study. Resuscitation. 2001;51:275-81

14. Kim YM, Yim HW, Jeong SH, Klem ML, Callaway CW. Does therapeutic hypothermia benefit adult cardiac arrest patients presenting with non-shockable initial rhythms? A systematic review and meta-analysis of randomized and non-randomized studies. Resuscitation. 2012;83:188-96.

15. Dumas F, Grimaldi D, Zuber B, Fichet J, Charpentier J, Pene F, et al. Is Hypothermia After Cardiac Arrest Effective in Both Shockable and Nonshockable Patients? Insights From a Large Registry. Circulation. 2011;123:877-86

16. Vaahersalo J, Hiltunen P, Tiainen M, Oksanen T, Kaukonen KM, Kurola J, et al. Therapeutic hypothermia after out-of-hospital cardiac arrest in Finnish intensive care units: the FINNRESUSCI study. Intensive Care Med. 2013;39:826-37.

17. Rd P, Jung C, Purle S, Lauten A, Yilmaz A, Surber R, et al. Survival does not improve when therapeutic hypothermia is added to post-cardiac arrest care. Resuscitation. 2011;82:1168-73.

18. Storm C, Nee J, Roser M, Jorres A, Hasper D. Mild hypothermia treatment in patients resuscitated from non-shockable cardiac arrest. Emerg Med J. 2012;29:100-3.

19. Nielsen N, Wetterslev J, Cronberg T, Erlinge D, Gasche Y, Hassager C, et al. Targeted temperature management at 33 degrees $C$ versus 36 degrees $C$ after cardiac arrest. N Engl J Med. 2013;369:2197-206.

20. Frydland $M$, Kjaergaard J, Erlinge D, Wanscher M, Nielsen N, Pellis T, et al. Target temperature management of $33^{\circ} \mathrm{C}$ AND $36^{\circ} \mathrm{C}$ in patients with out-of-hospital cardiac arrest with initial non-shockable rhythm. A TTM sub-study. Resuscitation. 2015.

21. Testori C, Sterz F, Behringer W, Haugk M, Uray T, Zeiner A, et al. Mild therapeutic hypothermia is associated with favourable outcome in patients after cardiac arrest with non-shockable rhythms. Resuscitation. 2011:82:1162-7.

22. Horburger D, Testori C, Sterz F, Herkner H, Krizanac D, Uray T, et al. Mild therapeutic hypothermia improves outcomes compared with normothermia in cardiac-arrest patients-a retrospective chart review. Crit Care Med. 2012, Publish Ahead of Print:10.1097/CCM.1090b1013e31825333cf.

23. Lundbye JB, Rai M, Ramu B, Hosseini-Khalili A, Li D, Slim HB, et al. Therapeutic hypothermia is associated with improved neurologic outcome and survival in cardiac arrest survivors of non-shockable rhythms. Resuscitation. 2012;83:202-7.

24. Larsen JM, Ravkilde J. Acute coronary angiography in patients resuscitated from out-of-hospital cardiac arrest-a systematic review and meta-analysis. Resuscitation. 2012;83:1427-33.

25. Wissenberg M, Lippert FK, Folke F, Weeke P, Hansen CM, Christensen EF, et al. Association of national initiatives to improve cardiac arrest management with rates of bystander intervention and patient survival after out-of-hospital cardiac arrest. JAMA. 2013:310:1377-84.

26. Soholm H, Hassager C, Lippert F, Winther-Jensen M, Hartvig-Thomsen J, Friberg $\mathrm{H}$, et al. Factors Associated With Successful Resuscitation After Out-of-Hospital Cardiac Arrest and Temporal Trends in Survival and Comorbidity. Ann Emerg Med. 2014

27. Lindner TW, Soreide E, Nilsen OB, Torunn MW, Lossius HM. Good outcome in every fourth resuscitation attempt is achievable-an Utstein template report from the Stavanger region. Resuscitation. 2011:82:1508-13.

28. Dumas F, White L, Stubbs BA, Cariou A, Rea TD. Long-Term Prognosis Following Resuscitation From Out of Hospital Cardiac Arrest: Role of Percutaneous Coronary Intervention and Therapeutic Hypothermia. J Am Coll Cardiol. 2012;60:21-7

29. Hagihara A, Hasegawa M, Abe T, Nagata T, Wakata Y, Miyazaki S. Prehospital epinephrine use and survival among patients with out-of-hospital cardiac arrest. JAMA. 2012;307:1161-8.

30. Atiksawedparit P, Rattanasiri S, McEvoy M, Graham CA, Sittichanbuncha $Y$, Thakkinstian A. Effects of prehospital adrenaline administration on out-of-hospital cardiac arrest outcomes: a systematic review and meta-analysis. Crit Care. 2014;18:463.
31. Goto Y, Maeda T, Goto Y. Effects of prehospital epinephrine during out-of-hospital cardiac arrest with initial non-shockable rhythm: an observational cohort study. Crit Care. 2013;17:R188.

32. Jacobs S, Hunt R, Tarnow-Mordi W, Inder T, Davis P. Cooling for newborns with hypoxic ischaemic encephalopathy. Cochrane Database Syst Rev. 2007:CD003311

33. Azzopardi D, Strohm B, Marlow N, Brocklehurst P, Deierl A, Eddama O, et al. Effects of Hypothermia for Perinatal Asphyxia on Childhood Outcomes. New Engl Jo Med. 2014;371:140-9.

34. Wee JH, Park KN, Oh SH, Youn CS, Kim HJ, Choi SP. Outcome analysis of cardiac arrest due to hanging injury. Am J Emerg Med. 2012;30:690-4.

35. Borgquist $\mathrm{O}$, Friberg $\mathrm{H}$. Therapeutic hypothermia for comatose survivors after near-hanging. A retrospective analysis. Resuscitation. 2009;80:210-2.

36. Baldursdottir S, Sigvaldason K, Karason S, Valsson F, Sigurdsson GH. Induced hypothermia in comatose survivors of asphyxia: a case series of 14 consecutive cases. Acta Anaesthesiol Scand. 2010;54:821-6.

37. Sadaka F. Therapeutic hypothermia for brain injury from near hanging: review of the literature. Therapeutic Hypothermia Temp Manag. 2013;3:13-6.

38. Geurts M, Macleod MR, Kollmar R, Kremer PH, van der Worp HB. Therapeutic hypothermia and the risk of infection: a systematic review and meta-analysis. Crit Care Med. 2014;42:231-42.

39. Perbet S, Mongardon N, Dumas F, Bruel C, Lemiale V, Mourvillier B, et al. Early onset pneumonia after cardiac arrest: characteristics, risk factors and influence on prognosis. Am J Respir Crit Care Med. 2011;184:1048-54.

40. Legriel S, Hilly-Ginoux J, Resche-Rigon M, Merceron S, Pinoteau J, Henry-Lagarrigue $M$, et al. Prognostic value of electrographic postanoxic status epilepticus in comatose cardiac-arrest survivors in the therapeutic hypothermia era. Resuscitation. 2013:84:343-50

41. Fairchild KD, Singh IS, Patel S, Drysdale BE, Viscardi RM, Hester L, et al. Hypothermia prolongs activation of NF-KB and augments generation of inflammatory cytokines. Am J Physiol Cell Physiol. 2004;287:C422-31.

42. Leary M, Grossestreuer AV, lannacone S, Gonzalez M, Shofer FS, Povey C, et al. Pyrexia and neurologic outcomes after therapeutic hypothermia for cardiac arrest. Resuscitation. 2013;84:1056-61

43. Bro-Jeppesen J, Hassager C, Wanscher M, Soholm H, Thomsen JH, Lippert FK, et al. Post-hypothermia fever is associated with increased mortality after out-of-hospital cardiac arrest. Resuscitation. 2013:84:1734-40.

44. Annborn M, Bro-Jeppesen J, Nielsen N, Ullen S, Kjaergaard J, Hassager C, et al. The association of targeted temperature management at 33 and 36 degrees $C$ with outcome in patients with moderate shock on admission after out-of-hospital cardiac arrest: a post hoc analysis of the Target Temperature Management trial. Intensive Care Med. 2014;40:1210-9.

45. Deye N, Arrich J, Cariou A. To cool or not to cool non-shockable cardiac arrest patients: it is time for randomized controlled trials. Intensive Care Med. 2013;39:966-9.

46. Pittl U, Schratter A, Desch S, Diosteanu R, Lehmann D, Demmin K, et al. Invasive versus non-invasive cooling after in- and out-of-hospital cardiac arrest: a randomized trial. Clin Res Cardiol. 2013;102:607-14

47. Tomte O, Draegni T, Mangschau A, Jacobsen D, Auestad B, Sunde K. A comparison of intravascular and surface cooling techniques in comatose cardiac arrest survivors. Crit Care Med. 2011;39:443-9.

48. Kim F, Olsufka M, Carlbom D, Deem S, Longstreth Jr WT, Hanrahan M, et al. Pilot study of rapid infusion of $2 \mathrm{~L}$ of 4 degrees $C$ normal saline for induction of mild hypothermia in hospitalized, comatose survivors of out-of-hospital cardiac arrest. Circulation. 2005;112:715-9.

49. Kim F, Olsufka M, Longstreth WT, Maynard C, Carlbom D, Deem S, et al. Pilot Randomized Clinical Trial of Prehospital Induction of Mild Hypothermia in Out-of-Hospital Cardiac Arrest Patients With a Rapid Infusion of $4^{\circ} \mathrm{C}$ Normal Saline. Circulation. 2007:115:3064-70.

50. Bernard SA, Smith K, Cameron P, Masci K, Taylor DM, Cooper DJ, et al. Induction of prehospital therapeutic hypothermia after resuscitation from nonventricular fibrillation cardiac arrest. Crit Care Med. 2011;40:747-53.

51. Poblete B, Romand JA, Pichard C, Konig P, Suter PM. Metabolic effects of i.v. propacetamol, metamizol or external cooling in critically ill febrile sedated patients. Br J Anaesth. 1997;78:123-7.

52. Ely EW, Truman B, Shintani A, Thomason JW, Wheeler AP, Gordon S, et al. Monitoring sedation status over time in ICU patients: reliability and validity of the Richmond Agitation-Sedation Scale (RASS). JAMA. 2003;289:2983-91.

53. Lascarrou JB, Le Gouge A, Dimet J, Lacherade JC, Martin-Lefevre L, Fiancette $M$, et al. Neuromuscular blockade during therapeutic hypothermia after 
cardiac arrest: observational study of neurological and infectious outcomes. Resuscitation. 2014;85:1257-62.

54. May T, Seder DB, Fraser GL, Tu C, McCrum B, Lucas L, et al. Association of the Bedside Shivering Assessment Scale and derived EMG power during therapeutic hypothermia in survivors of cardiac arrest. Resuscitation. 2011;82:1100-3.

55. Badjatia N, Strongilis E, Gordon E, Prescutti M, Fernandez L, Fernandez A, et al. Metabolic impact of shivering during therapeutic temperature modulation: the Bedside Shivering Assessment Scale. Stroke. 2008:39:3242-7.

56. Voicu S, Deye N, Malissin I, Vigue B, Brun PY, Haik W, et al. Influence of alpha-stat and pH-stat blood gas management strategies on cerebral blood flow and oxygenation in patients treated with therapeutic hypothermia after out-of-hospital cardiac arrest: a crossover study. Crit Care Med. 2014;42:1849-61.

57. Cronberg T, Horn J, Kuiper MA, Friberg H, Nielsen N. A structured approach to neurologic prognostication in clinical cardiac arrest trials. Scand J Trauma Resusc Emerg Med. 2013;21:45

58. Daubin C, Bornstain C, Graftieaux J, Thirion M, Régnier B. Avis de la CE-SRLF sur la démarche de prise de décision de limitation ou d'arrêt des thérapeutiques chez l'adulte en coma postanoxique après un arrêt cardiaque. Réanimation. 2012;21:637-44.

59. Jennett B, Bond M. Assessment of outcome after severe brain damage: a pratical scale. Lancet. 1975;305:480-4.

60. Cummins R, Chamberlain D, Abramson N, Allen M, Baskett P, Becker L, et al. Recommended guidelines for uniform reporting of data from out-of- hospital cardiac arrest: the Utstein Style. A statement for health professionals from a task force of the American Heart Association, the European Resuscitation Council, the Heart and Stroke Foundation of Canada, and the Australian Resuscitation Council. Circulation. 1991;84:960-75.

61. Stiell IG, Nesbitt LP, Nichol G, Maloney J, Dreyer J, Beaudoin T, et al. Comparison of the Cerebral Performance Category Score and the Health Utilities Index for Survivors of Cardiac Arrest. Ann Emerg Med. 2009;53:241-8. e241.

62. Fayol P, Carriere H, Habonimana D, Preux PM, Dumond JJ. French version of structured interviews for the Glasgow Outcome Scale: guidelines and first studies of validation. Annales de readaptation et de medecine physique: revue scientifique de la Societe francaise de reeducation fonctionnelle de readaptation et de medecine physique. 2004:47:142-56.

63. Moulaert VR, Wachelder EM, Verbunt JA, Wade DT, van Heugten CM. Determinants of quality of life in survivors of cardiac arrest. J Rehabil Med. 2010:42:553-8

64. Keller SD, Ware Jr JE, Bentler PM, Aaronson NK, Alonso J, Apolone G, et al. Use of structural equation modeling to test the construct validity of the SF-36 Health Survey in ten countries: results from the IQOLA Project. International Quality of Life Assessment. J Clin Epidemiol. 1998;51:1179-88.

65. Katz S, Downs TD, Cash HR, Grotz RC. Progress in development of the index of ADL. Gerontologist. 1970;10:20-30.

66. Katz S, Ford AB, Moskowitz RW, Jackson BA, Jaffe MW. Studies of illness in the aged. The index of ADL: a standardized measure of biological and psychosocial function. JAMA. 1963;185:914-9.

67. Della Pietra GL, Savio K, Oddone E, Reggiani M, Monaco F, Leone MA. Validity and reliability of the Barthel index administered by telephone. Stroke. 2011:42:2077-9.

68. Longstreth WT, Nichol G, Van Ottingham L, Hallstrom AP. Two simple questions to assess neurologic outcomes at 3 months after out-of-hospital cardiac arrest: Experience from the Public Access Defibrillation Trial. Resuscitation. 2010;81:530-3.

69. Roccaforte WH, Burke WJ, Bayer BL, Wengel SP. Validation of a telephone version of the mini-mental state examination. J Am Geriatr Soc. 1992;40:697-702

70. Horowitz M, Wilner N, Alvarez W. Impact of Event Scale: a measure of subjective stress. Psychosom Med. 1979;41:209-18.

71. Contentin L, Ehrmann S, Giraudeau B. Heterogeneity in the definition of mechanical ventilation duration and ventilator-free days. Am J Respir Crit Care Med. 2014;189:998-1002.

72. Schulz KF, Altman DG, Moher D. CONSORT 2010 statement: updated guidelines for reporting parallel group randomised trials. BMJ. 2010;340:c332
73. Peto R, Pike MC, Armitage P, Breslow NE, Cox DR, Howard SV, et al. Design and analysis of randomized clinical trials requiring prolonged observation of each patient. I Introduction and design. Br J Cancer. 1976;34:585-612.

74. Kagawa E, Inoue I, Kawagoe T, Ishihara M, Shimatani Y, Kurisu S, et al. Who benefits most from mild therapeutic hypothermia in coronary intervention era? A retrospective and propensity-matched study. Crit Care. 2010;14:R155.

75. Drennan IR, Lin S, Thorpe KE, Morrison LJ. The effect of time to defibrillation and targeted temperature management on functional survival after out-of-hospital cardiac arrest. Resuscitation. 2014;85(11):1623-8.

76. Testori C, Sterz F, Holzer M, Losert H, Arrich J, Herkner H, et al. The beneficial effect of mild therapeutic hypothermia depends on the time of complete circulatory standstill in patients with cardiac arrest. Resuscitation. 2012;83:596-601.

77. Lopez-de-Sa E, Rey JR, Armada E, Salinas P, Viana-Tejedor A, Espinosa-Garcia $S$, et al. Hypothermia in comatose survivors from out-of-hospital cardiac arrest: pilot trial comparing 2 levels of target temperature. Circulation. 2012:126:2826-33.

78. Winters SA, Wolf KH, Kettinger SA, Seif EK, Jones JS, Bacon-Baguley T. Assessment of risk factors for post-rewarming "rebound hyperthermia" in cardiac arrest patients undergoing therapeutic hypothermia. Resuscitation. 2013;84:1245-9.

\section{Submit your next manuscript to BioMed Central and take full advantage of:}

- Convenient online submission

- Thorough peer review

- No space constraints or color figure charges

- Immediate publication on acceptance

- Inclusion in PubMed, CAS, Scopus and Google Scholar

- Research which is freely available for redistribution 